\title{
Comparative Analysis of Serum Zinc, Copper and Magnesium Level and Their Relations in Association with Severity and Mortality in SARS-CoV-2 Patients
}

\author{
Kiran Kumar PVSN ${ }^{1}$ - Sojit Tomo ${ }^{1}$. Purvi Purohit ${ }^{1}$ - Shrimanjunath Sankanagoudar ${ }^{1}$. Jayakaran Charan ${ }^{2}$. \\ Abhishek Purohit ${ }^{3} \cdot$ Vijaylakshami Nag ${ }^{4} \cdot$ Pradeep Bhatia $^{5} \cdot$ Kuldeep Singh $^{6} \cdot$ Naveen Dutt $^{7} \cdot$ Mahendra Kumar Garg $^{8}$. \\ Praveen Sharma ${ }^{1} \cdot$ Sanjeev Misra ${ }^{9} \cdot$ Dharamveer Yadav $^{1}$
}

Received: 21 December 2021 / Accepted: 17 January 2022 / Published online: 22 January 2022

(c) The Author(s), under exclusive licence to Springer Science+Business Media, LLC, part of Springer Nature 2022

\begin{abstract}
The deficiencies of trace elements and infectious diseases often coexist and exhibit complex interactions. Several trace elements such as zinc $(\mathrm{Zn})$, copper $(\mathrm{Cu})$ and magnesium $(\mathrm{Mg})$ have immunomodulatory functions and thus influence the susceptibility to the course and outcome of a variety of viral infections. So, this present study was aimed to study relations of trace metals in association with severity and mortality in SARS-CoV-2 patients. A total of 150 individuals infected with COVID-19 and 50 healthy individuals were recruited. Cases were divided based on severity (mild, moderate and severe) and outcome (discharged or deceased). Serum $\mathrm{Zn}, \mathrm{Mg}$ and $\mathrm{Cu}$ levels were analysed by direct colourimetric method. Both serum $\mathrm{Cu}$ and $\mathrm{Zn}$ levels were significantly decreased in cases when compared to those in controls $(p<0.005$ and $p<0.0001)$. Serum magnesium levels although not significant were found to be slightly decreased in controls. On comparing the trace elements between the deceased and discharged cases, a significant difference was found between serum copper and zinc levels, but for magnesium, both groups have similar levels. The receiver operating characteristic (ROC) curve results indicate that a serum $\mathrm{Cu} / \mathrm{Zn}$ ratio along with the age of patient provides some reliable information on COVID-19 course and survival odds by yielding an AUC of $95.1 \%$ with a sensitivity of $93.8 \%$ and specificity of $89.8 \%$. Therefore, we would like to emphasize that measuring the serum copper and zinc along with their ratio can be used as routine investigations for COVID-19 patients in proper identification and management of severe cases in upcoming new waves of COVID-19.
\end{abstract}

Keywords Trace metals $\cdot$ Copper $\cdot$ Zinc $\cdot$ Magnesium $\cdot$ COVID-19

\section{Introduction}

Coronavirus disease (COVID-19) is an infectious disease caused by the severe acute respiratory distress syndromeassociated coronavirus 2 (SARS-CoV-2). [1]. COVID-19

Dharamveer Yadav

dharam143s@gmail.com

1 Department of Biochemistry, All India Institute of Medical Sciences, Basni, Jodhpur, Rajasthan 342005, India

2 Department of Pharmacology, All India Institute of Medical Sciences, Jodhpur, India

3 Department of Pathology, All India Institute of Medical Sciences, Jodhpur, India

4 Department of Microbiology, All India Institute of Medical Sciences, Jodhpur, India presents with a different phenotypic presentation ranging from asymptomatic presentation to grave presentation causing multiple organ dysfunction syndromes (MODS) and finally death [2-4]. Organ dysfunction, particularly progressive respiratory failure and generalized
5 Department of Anaesthesia, All India Institute of Medical Sciences, Jodhpur, India

6 Department of Paediatrics, All India Institute of Medical Sciences, Jodhpur, India

7 Department of Pulmonary Medicine, All India Institute of Medical Sciences, Jodhpur, India

8 Department of General Medicine, All India Institute of Medical Sciences, Jodhpur, India

9 Department of Surgical Oncology, Director and CEO, All India Institute of Medical Sciences, Jodhpur, Rajasthan, India 
coagulopathy, is associated with the highest mortality [5]. Now, the number of infected people has reached 200 million with 43 million deaths around the world, and the infected people are not restricted by any race and borders.

Nutrition status plays an important role in maintaining general health. Deficiency of micronutrients is recognized as a global health issue. Similar to macronutrients, micronutrients also have an equal role in developing and maturing of the immune response [6]. Although contradictory data exist, many recent studies indicate that micronutrients with immune-supporting roles may modulate immune function and reduce the risk of infection [7]. Trace elements such as zinc $(\mathrm{Zn})$, copper $(\mathrm{Cu})$ and magnesium $(\mathrm{Mg})$ have immunomodulatory functions and thus influence the susceptibility of the course and outcome of a variety of viral infections [8].

Copper $(\mathrm{Cu})$ plays a significant role in the maintenance of the immune system. It plays a major role in the elimination of the virus by acting on the NK cells. Accordingly, copper deficiency is associated with several symptoms that are related to $\mathrm{Cu}$-containing enzymes. One such enzyme is superoxide dismutase which prevents cell injury from oxidative damage [9]. So, any copper deficiency was found to be associated with decreased immune response leading to many viral and bacterial infections in both young and elderly people [10]. Many previous studies have also shown that copper supplementation has a positive effect on the inhibition of viral replication [11,12]. Similar studies on novel coronavirus found that SARS-CoV-2 (COVID19) is more sensitive to $\mathrm{Cu}$ surface contact compared to SARS-CoV-1 [13].

Zinc ( $\mathrm{Zn})$ is an essential trace element that plays a vital role in antiviral immunity and anti-inflammatory properties [14, 15]. Zinc is involved in regulating the function of immune cells such as NK cells, monocytes, neutrophils and $\mathrm{T}$ and $\mathrm{B}$ lymphocytes. Zinc is found to maintain the structure and function of the respiratory epithelium barrier. Following a respiratory viral infection, these cells are recruited to the respiratory tissue. It seems that zinc can enhance the proliferation of $\mathrm{CD} 8+$ cytotoxic $\mathrm{T}$ lymphocytes. These cells are crucial in the immune response to respiratory viruses [16]. Disorders in the integrity of the respiratory epithelium can promote virus entry [17]. In a recent clinical study, significant improvement was shown by SARS-CoV-19 outpatients when treated with zinc supplements [18].

$\mathrm{Mg}^{2+}$ is an essential mineral with pleiotropic effects on cellular functions. It acts as a cofactor for several important enzymes such as kinases which regulate the cytotoxic $T$ cell activation during infections [19]. In a recent study by Ye et al. (2020), serum Mg was found to have a protective effect in COPD patients, which can explain the relationship between the $\mathrm{Mg}$ and the pulmonary outcomes of COVID19 [20].
This study was aimed to evaluate the status of zinc, copper and magnesium in individuals diagnosed with SARS-CoV-2.

\section{Materials and Methods}

\section{Study Design}

A cross-sectional comparative study was conducted in one of the isolation centres dedicated for the COVID-19 patients in All India Institute of Medical Sciences, Jodhpur, India.

\section{Study Population}

A total of 150 individuals who were diagnosed and admitted with SARS-CoV-2 were recruited from the COVID-19 isolation wards of All India Institute of Medical Sciences, Jodhpur. Based on the severity and the symptoms, these 150 patients were divided into mild, moderate and severe groups with each group having 50 individuals. Another 50 individuals were included as healthy controls. Further, the cases were also divided based on the outcome. The diagnosis was made based on the RT-PCR test [21]. All participants had given written informed consent before participating in the study, and their anonymity was preserved. The study was performed as per the ethical standards established in the Declaration of Helsinki and was approved by the institutional ethics committee.

\section{Specimen Collection and Determination of the Trace Elements}

Three millilitres of peripheral venous blood were drawn from the participants, and serum was obtained after centrifuging at 10,000 rpm for $5 \mathrm{~min}$; the serum was further stored in an Eppendorf tube at $-20^{\circ} \mathrm{C}$ for determination of $\mathrm{Cu}, \mathrm{Zn}$ and $\mathrm{Mg}$.

Serum zinc, copper and magnesium were measured using the DiaSys kit (DiaSys Diagnostic Systems, Germany) on Beckman-Coulter/AU480 system (Beckman-Coulter, USA). Quality control materials were obtained from the TruLab normal control for clinical chemistry (DiaSys Diagnostic Systems, Germany).

\section{Statistical Analysis}

The data collected were tabulated and analysed using Microsoft Excel and SPSS version 20 for Windows (Chicago, IL, USA). The data collected were analysed using Microsoft Excel and SPSS version 21.0 (IBM SPSS Statistics, USA) for Windows. The data are expressed as median and IQR. Categorical variables were calculated as frequency and 
percentage; continuous variables were represented as median (IQR). The normality of the parameters was checked using the Shapiro-Wilk test and found to be non-parametric. The difference in serum trace elements levels between subgroups was analysed using Kruskal-Wallis and Mann-Whitney $U$ test along with pairwise post-hoc analysis. Moreover, Spearman correlation analysis was used to find the significance of association between the variables. Variable selection for ROC was performed via stepwise AIC selection. Differences between ROC curves were assessed by the DeLong test for two correlated ROC curves. A $p$ value $<0.05$ was considered statistically significant.

\section{Results}

A total of 200 study participants were included in the study, of which 150 were diagnosed with COVID-19 and 50 were healthy controls. Further, the cases were classified into mild, moderate and severe groups of 50 each based on their admission into different wards. The demographic, biochemical and haematological parameters are presented in Table 1.

The median levels of magnesium, copper and zinc of the total cases were $2.26 \mathrm{mg} / \mathrm{dl}, 144.31 \mu \mathrm{g} / \mathrm{dL}$ and $56.61 \mu \mathrm{g} / \mathrm{dL}$, respectively. Similarly, median levels of magnesium, copper and zinc of the controls were $2.24 \mathrm{mg} / \mathrm{dl}, 150.66 \mu \mathrm{g} / \mathrm{dL}$ and $60.50 \mu \mathrm{g} / \mathrm{dL}$, respectively. A significant difference was found between the levels of copper and zinc when compared between the total cases and the controls. Both the serum $\mathrm{Cu}$ and $\mathrm{Zn}$ levels were significantly decreased in cases when compared to those in the controls $(p<0.005$ and $p<0.0001)$. Serum magnesium levels although not significant were found to be slightly decreased in controls when compared to those in the cases (Table 2).

Similarly, on comparing the different groups of cases and the control of baseline samples of the COVID-19 patients, a significant difference was found between the levels of copper and zinc. Serum $\mathrm{Zn}$ levels in total cases were $8 \%$ lower than the respective values in the control group. These levels were found to be decreasing with the increasing severity of
Table 1 Demographic and biochemical parameters of the study population

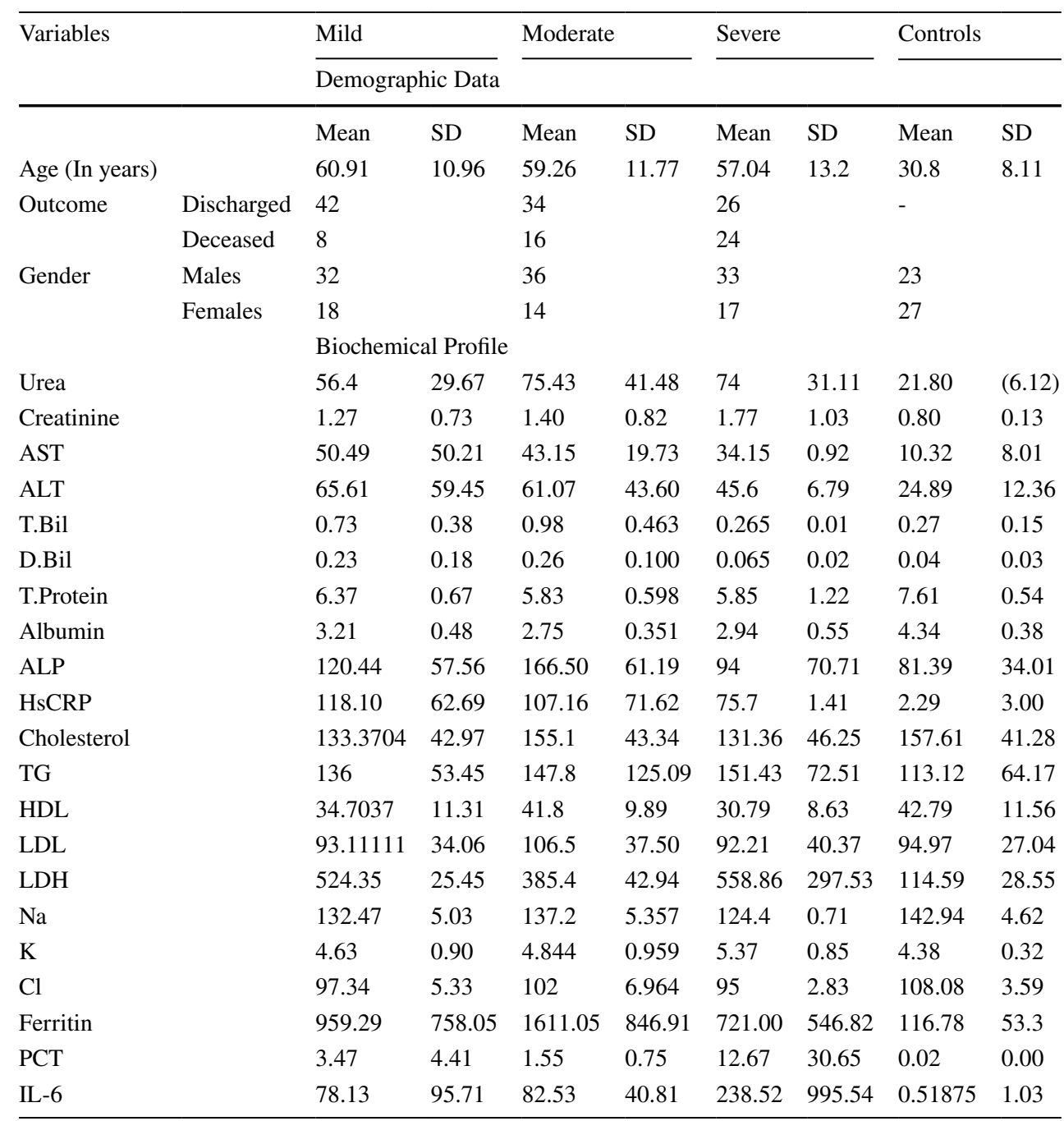


Table 2 Comparison of metals between COVID-19 cases and controls on baseline sample

\begin{tabular}{lllll}
\hline & & Magnesium & Copper & Zinc \\
\hline Control & $N$ & 50 & 50 & 50 \\
& Median & 2.24 & 150.66 & 60.50 \\
& 25th percentile & 2.13 & 118.85 & 48.22 \\
& 75th percentile & 2.36 & 140.96 & 74.59 \\
COVID-19 & $N$ & 150 & 150 & 150 \\
& Median & 2.26 & 144.31 & 56.61 \\
& 25th percentile & 1.97 & 125.58 & 45.06 \\
& 75th percentile & 2.41 & 165.1 & 73.08 \\
& $p$ value & 0.7545 & $\mathbf{0 . 0 0 5 0}$ & $<\mathbf{0 . 0 0 0 1}$ \\
\hline
\end{tabular}

Statistical test: Mann-Whitney test

All bold values signifies $p<0.05$

the groups with median levels of mild, moderate and severe $56.7 \mu \mathrm{g} / \mathrm{dL}, 50.5 \mu \mathrm{g} / \mathrm{dL}$ and $42.89 \mu \mathrm{g} / \mathrm{dL}$, respectively, i.e. being $7 \%, 16 \%$ and $30 \%$ lower when compared to healthy controls. A similar trend was also observed in the serum $\mathrm{Cu}$ levels. Serum $\mathrm{Cu}$ concentrations in patients with mild, moderate and severe COVID-19 were $2 \%, 5 \%$ and $15 \%$, respectively, lower than those in healthy subjects. No significant difference or trend in serum $\mathrm{Mg}$ levels was found between the cases and controls (Table 3 ).

Further the cases were divided based on the outcome, $42 \%$ of the total cases had a fatal outcome, of which $16 \%$

Table 3 Comparison of metals between different grades of COVID19 cases and controls on the baseline sample

\begin{tabular}{lllll}
\hline & & Magnesium & Copper & Zinc \\
\hline Control & $N$ & 50 & 50 & 50 \\
& Median & 2.24 & 150.66 & 60.50 \\
& 25th percentile & 2.13 & 118.85 & 48.22 \\
& 75th percentile & 2.36 & 140.96 & 74.59 \\
Mild COVID-19 & $N$ & 50 & 50 & 50 \\
& Median & 2.26 & 145.41 & 56.705 \\
& 25th percentile & 1.93 & 133.1 & 48.84 \\
& 75th percentile & 2.39 & 164.41 & 72.95 \\
Moderate COVID- & $N$ & 50 & 50 & 50 \\
& Median & 2.28 & 135.755 & 50.595 \\
& 25th percentile & 2.17 & 125.66 & 39.08 \\
& 75th percentile & 2.42 & 158.38 & 69.12 \\
Severe COVID-19 & $N$ & 50 & 50 & 50 \\
& Median & 2.23 & 148.22 & 42.89 \\
& 25th percentile & 1.91 & 121.66 & 39.65 \\
& 75th percentile & 2.53 & 167.29 & 47.53 \\
& $p$ value & 0.3727 & $\mathbf{0 . 0 3 0 8}$ & $\mathbf{0 . 0 0 0 1}$ \\
\hline
\end{tabular}

Statistical test: Kruskal-Wallis

All bold values signifies $p<0.05$ were from mild cases, $33 \%$ were from moderate cases and $49 \%$ were from severe cases. On comparing the trace elements between the deceased and the discharged cases, a significant difference was between the serum copper and zinc levels, but for magnesium, both the groups have similar levels. Similarly, on comparing these individuals with the controls, we found that although not significant both deceased and discharged individuals were having higher levels of serum magnesium. Similarly, for serum copper and zinc, lower levels were found in the deceased, but the difference was significant only in the serum zinc levels. We also found a significant difference in the levels of zinc $(p<0.0014)$ when compared between the controls, discharged and deceased individuals. No significant change was found in the levels of serum magnesium $(p=0.154)$, serum copper $(p=0.82)$ and $\mathrm{Cu} / \mathrm{Zn}$ ratio $(p=0.15)$.

Further, on comparing the baseline and follow-up samples of discharged patients, the serum levels of $\mathrm{Cu}, \mathrm{Zn}$ and $\mathrm{Mg}$ have been increased approximately 2 to $5 \%$ each in follow-up samples, but the difference was not found to be significant. A similar non-significant increase in the levels of serum $\mathrm{Cu}, \mathrm{Zn}$ and $\mathrm{Mg}$ was found in the different grades of follow-up samples when compared to the baseline samples (Table 4). Since serum $\mathrm{Cu}$ and $\mathrm{Zn}$ levels were known to have a significant bidirectional change, we have evaluated the $\mathrm{Cu} /$ $\mathrm{Zn}$ ratio. On comparing the ratios, a significant difference was found between the cases and controls. Similarly, we have found that these values were found to be decreasing gradually in association with COVID-19 severity.

Correlation analysis was performed to determine the relationship between serum metal levels (baseline) and markers of the disease severity. A significant positive correlation was found between serum Mg levels and ferritin levels. Although not significant, a weak negative correlation was found with IL-6 levels. A similar significant negative correlation was found between the serum copper and zinc levels with IL-6 levels. A non-significant weak negative correlation was

Table 4 Comparison of metals in COVID-19 cases between baseline and follow-up sample of discharged patients

\begin{tabular}{lllll}
\hline & & Magnesium & Copper & Zinc \\
\hline Baseline & $N$ & 87 & 87 & 87 \\
& Median & 2.26 & 144.31 & 56.61 \\
& 25th percentile & 1.97 & 125.58 & 45.06 \\
& 75th percentile & 2.41 & 165.1 & 73.08 \\
Follow-up & $N$ & 150 & 150 & 150 \\
& Median & 2.26 & 148.28 & 61.33 \\
& 25th percentile & 1.97 & 124.61 & 48.21 \\
& 75th percentile & 2.47 & 165.70 & 74.42 \\
& $p$ value & 0.2211 & 0.4837 & 0.2566 \\
\hline
\end{tabular}

Statistical test: Wilcoxon signed-rank test 
found between the serum $\mathrm{Zn}$ levels and ferritin, hsCRP and procalcitonin levels (Table 5).

Finally, receiver operating characteristic (ROC) curve analyses were conducted to estimate the value of $\mathrm{Cu}, \mathrm{Zn}$ and $\mathrm{Mg}$ status as biomarkers for knowing the status of survival in COVID-19 (Fig. 1a and 1b). Serum $\mathrm{Cu}, \mathrm{Zn}$, $\mathrm{Mg}$ as well as $\mathrm{Cu} / \mathrm{Zn}$ concentrations were tested alone and in combination by a stepwise AIC method using regression analysis. The area under ROC curve (AUC) for serum zinc, copper and copper/zinc ratio was $0.75,0.63$ and 0.64 , and $95 \%$ confidence interval $(95 \% \mathrm{CI})$ was $0.68-0.81$, $0.56-0.70$ and $0.56-0.71$, respectively. Pairwise comparison of ROC curves was presented in Table 6. On combining the age and the copper/zinc ratio, the AUC curve was increased to $95.1 \%$. The results indicate that a serum $\mathrm{Cu} / \mathrm{Zn}$ ratio along with the age of patient provides some reliable information on COVID-19 course and survival odds by yielding an AUC of 95.1\%. Cutoff point based on
Table 5 Correlation analysis of baseline metals with inflammatory parameters in COVID-19 patients
Fig. 1 a Receiver operating characteristic (ROC) curves of copper, zinc, magnesium and $\mathrm{Cu} / \mathrm{Zn}$ ratio in relation to survival in COVID-19 patients. b The multiple regression model based on $\mathrm{Cu} / \mathrm{Zn}$ and the patient's age outperformed any other combination of variables via stepwise AIC selection. The final model, based on these two parameters, yielded the highest AUC of $95.1 \%$

\begin{tabular}{|c|c|c|c|c|c|c|}
\hline & \multicolumn{2}{|c|}{ Magnesium } & \multicolumn{2}{|l|}{ Copper } & \multicolumn{2}{|l|}{ Zinc } \\
\hline & Rho & $p$ value & Rho & $p$ value & Rho & $p$ value \\
\hline Ferritin & 0.5003 & $<0.0001$ & -0.1992 & 0.1175 & -0.0422 & 0.7426 \\
\hline PCT & 0.2206 & 0.1895 & 0.0225 & 0.9847 & -0.0786 & 0.6438 \\
\hline IL6 & -0.11 & 0.2556 & -0.35 & 0.025 & -0.2336 & 0.0483 \\
\hline hsCRP & 0.0480 & 0.6569 & 0.0071 & 0.9478 & -0.2042 & 0.0563 \\
\hline
\end{tabular}

All bold values signifies $p<0.05$
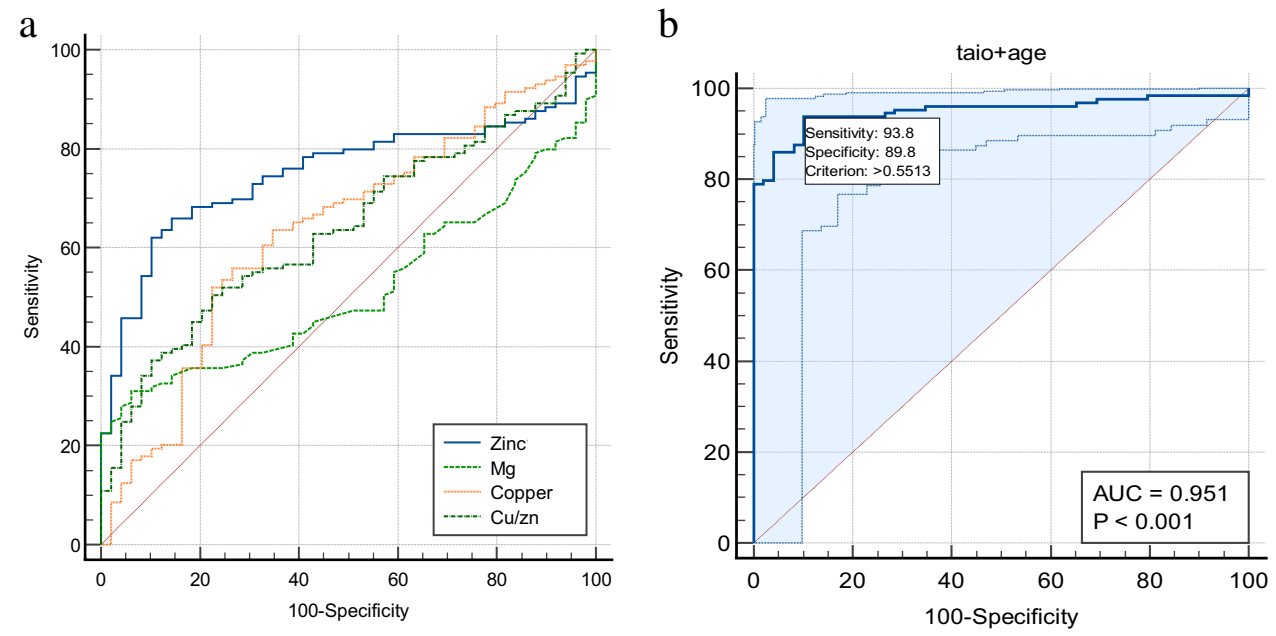

\begin{tabular}{lllll}
\hline Variable & AUC & SE & $95 \%$ CI & P value \\
\hline Zinc & 0.751 & 0.0364 & 0.681 to 0.813 & - \\
Magnesium & 0.515 & 0.0428 & 0.439 to 0.591 & - \\
Copper & 0.637 & 0.0462 & 0.561 to 0.707 & - \\
Cu/Zn ratio & 0.640 & 0.0427 & 0.565 to 0.710 & - \\
Pairwose Variable & Difference between areas & SE & $95 \%$ CI & \\
Zinc and Magnesium & 0.236 & 0.063 & 0.113 to 0.360 & 0.0002 \\
Zinc and Copper & 0.115 & 0.0567 & 0.00336 to 0.226 & 0.0435 \\
Zinc and Cu/Zn & 0.112 & 0.0309 & 0.0510 to 0.172 & 0.03 \\
Magnesium and Copper & 0.122 & 0.0667 & -0.00921 to 0.252 & 0.0685 \\
Magnesium and Cu/Zn & 0.125 & 0.0656 & -0.00408 to 0.253 & 0.0577 \\
Copper and Cu/Zn & 0.00301 & 0.0777 & -0.149 to 0.155 & 0.9692 \\
\hline
\end{tabular}

Table 6 Individual ROC and pairwise comparison of ROC curves 
Youden's $\mathrm{J}$ index is depicted by a sensitivity of $93.8 \%$ and a specificity of $89.8 \%$, with $p<0.0001$.

\section{Discussion}

An optimum level of the essential trace elements is necessary for the well-functioning and maintenance of the immune system during any infections. So, in this present study, we tried to evaluate serum trace elements and their association with the severity in the COVID-19 patients. The results indicate that these metal levels are altered in a severity-dependent manner, showing that trace elements place a major role in COVID-19 pathology.

Many recent reviews have commented that trace elements, vitamins and heavy metals play a major role in the pathophysiology of COVID-19 due to their pivotal role in homeostasis of the immune and other major systems of the body [22-25]. In vitro studies showed that SARS-CoV-2 viral spike protein interacts with ACE2 receptor, which is a zinc-dependent peptidyl dipeptide hydrolase. So, any imbalance of $\mathrm{Zn}$ adversely affects immune functions [26, 27]. Previous studies also reported that a decrease in zinc levels supports the ACE2 to SARS-CoV-2 spike protein and an increase will inhibit the ACE2 expression resulting in reduced viral interaction [28]. Further, the zinc deficiency also results in lymphoid atrophy and decreased $\mathrm{T}$ cell immunity. So, any imbalance of $\mathrm{Zn}$ also adversely affects immune functions [26]. In this study, serum zinc levels were found to be significantly decreased in the severe group when compared to mild, moderate and controls. Similar results were reported by Jothimani et al., where patients with lower zinc levels were associated with severe complications and longer hospital stays [29]. Many other studies including the pregnant population also reported decreased zinc levels in COVID-19-infected people [30,31]. To confirm the role of zinc in the disease progression, zinc supplements were also started besides the routine treatment in some studies; the groups which were not given any supplements were met with higher mortality compared to the population taking zinc supplements [32]. On the contrary, another similar study reported that treatment with zinc has no role in the COVID-19 outcome [16].

In contrast to zinc, we found that the serum copper levels were increased with the severity but were lower than those in the controls. Similar results were also reported in the Nigerian population by Muhammad et al. [33]. Our results were also in line with those of Zeng et al., who reported higher copper levels in both urine and blood of severe patients $[34,35]$. These findings are also in agreement with the serum $\mathrm{Cu}$ levels in COVID-19-infected pregnant women [30]. But a recent study proposed the use of copper as an adjunct therapy in a severely ill COVID-19 patient due to its role in antiviral defence mechanism, but they also emphasized that attention should be paid to copper toxicity $[36,37]$. However, in our study, the difference in serum copper levels in relation to severely ill patients is very small when compared to mild and moderate groups. Contrary to our results, a study in Germany did not find any relative change in serum copper levels during the hospital stay [38]. The recent study also found a weak and non-significant positive correlation with both PCT and hsCRP which is in agreement with the results of the study done by Fooladi et al. [37]. The $\mathrm{Cu} / \mathrm{Zn}$ ratio was also found to be more in controls when compared to that in the cases which is in line with the previous studies. The $\mathrm{Cu} / \mathrm{Zn}$ ratio was considered as the potential marker of inflammation in an elevated $\mathrm{Cu} / \mathrm{Zn}$ ratio was found to be associated with higher risk and mortality in infectious diseases shown to be associated with a higher risk of infectious diseases leading to hospitalization [39].

Magnesium is the most abundant intracellular cation after potassium, which plays a major role in most of the enzymatic reactions in our body. Magnesium deficiency promotes inflammation by activating the endothelial cells and thereby increasing the pro-inflammatory cytokines [40]. In this study, we did not find any significant change in the levels of serum magnesium between controls and cases as well as in between the different severity groups of cases. On the contrary, studies have mentioned that serum magnesium levels increase in severe patients when compared to nonsevere patients [41, 42].

Based on ROC curve analysis, this study suggests that age along with the copper to zinc ratio combined can help in estimating the survival odds in critically ill patients when compared with the serum zinc and copper levels alone. Similar results were reported by Yasui et al., where zinc and LDH values combined model can predict the critically ill patients of COVID-19 [43]. Similarly, Heller et al. also reported that age along with the zinc and selenoprotein values can predict the survival of the COVID-19 patients [44].

\section{Conclusion}

In conclusion, based on our results, severely ill patients showed decreased zinc levels and increased copper levels when compared to mild and moderate ill patients. But the overall levels were decreased when compared to the controls. In evaluating the relationship between the serum zinc, copper levels and age of the patients with severity of patients of COVID-19, it was suggested that the ROC curve with an AUC of $95.1 \%$ by only two factors, $\mathrm{Cu} / \mathrm{Zn}$ ratio and age, could help in knowing the survival odds in severe cases. Therefore, we would like to emphasize that measuring the serum copper and zinc levels along with their ratio can be 
used as routine investigations for COVID-19 patients in the proper identification and management of severe cases in the upcoming new waves of COVID-19.

Supplementary Information The online version contains supplementary material available at https://doi.org/10.1007/s12011-022-03124-7.

Author Contribution All authors contributed to the study conception and design. Material preparation, data collection and analysis were performed by PVSN Kiran Kumar, Sojit Tomo, Dharamveer Yadav and Purvi Purohit. The first draft of the manuscript was written by PVSN Kiran Kumar, Dharamveer Yadav and Purvi Purohit, and all authors commented on previous versions of the manuscript. All authors read and approved the final manuscript. Conceptualization: Dharamveer Yadav, Purvi Purohit and Shrimanjunath Sankanagoudar. Writing, review and editing: PVSN Kiran Kumar, Sojit Tomo, Dharamveer Yadav and Purvi Purohit. Sample testing: Abhishek Purohit and Vijaylakshami Nag. Patient recruiting: Naveen Dutt and Pradeep Bhatia. Supervision: Dharamveer Yadav, Kuldeep Singh, Mahendra Kumar Garg and Praveen Sharma. Funding: Sanjeev Misra.

Funding This work is supported by the intramural project grant by All India Institute of Medical Sciences, Jodhpur.

Data Availability The datasets generated during and/or analysed during the current study are part of institutional COVID-19 projects; in order to give the data publicly, we need permission from higher authorities (director). So, data are not publicly available but are available from the corresponding author on reasonable request.

\section{Declarations}

Ethics Approval This study was performed in line with the principles of the Declaration of Helsinki. Approval was granted by the institutional ethics committee.

Consent to Participate All participants has freely given informed consent to participate in the study.

Competing Interests The authors declare no competing interests.

\section{References}

1. Magro C, Mulvey JJ, Berlin D et al (2020) Complement associated microvascular injury and thrombosis in the pathogenesis of severe COVID-19 infection: a report of five cases. Transl Res 220:1-13. https://doi.org/10.1016/j.trsl.2020.04.007

2. Chang D, Lin M, Wei L et al (2020) Epidemiologic and clinical characteristics of novel coronavirus infections involving 13 patients outside Wuhan, China. JAMA 323:1092-1093. https:// doi.org/10.1001/jama.2020.1623

3. Li J, Gong X, Wang Z et al (2020) Clinical features of familial clustering in patients infected with 2019 novel coronavirus in Wuhan. China Virus Res 286:198043. https://doi.org/10.1016/j. virusres.2020.198043

4. Diao K, Han P, Pang T et al (2020) HRCT imaging features in representative imported cases of 2019 novel coronavirus pneumonia. Precis Clin Med 3:9-13. https://doi.org/10.1093/pcmedi/pbaa004

5. Tomo S, Kumar KP, Roy D et al (2021) Complement activation and coagulopathy - an ominous duo in COVID19. Expert Rev
Hematol 14:155-173. https://doi.org/10.1080/17474086.2021. 1875813

6. Stanimirovic B, Vujovic D, Pejin B et al (2019) A contribution to the elemental profile of the leaf samples of newly developed Cabernet Franc varieties. Nat Prod Res 33:1209-1213. https://doi. org/10.1080/14786419.2018.1457671

7. Gombart AF, Pierre A, Maggini S (2020) A review of micronutrients and the immune system-working in harmony to reduce the risk of infection. Nutrients 12:E236. https://doi.org/10.3390/ nu12010236

8. Maggini S, Pierre A, Calder PC (2018) Immune function and micronutrient requirements change over the life course. Nutrients 10:E1531. https://doi.org/10.3390/nu10101531

9. Li CX, Gleason JE, Zhang SX et al (2015) Candida albicans adapts to host copper during infection by swapping metal cofactors for superoxide dismutase. Proc Natl Acad Sci U S A 112:E53365342. https://doi.org/10.1073/pnas.1513447112

10. Percival SS (1998) Copper and immunity. Am J Clin Nutr 67:1064S-1068S. https://doi.org/10.1093/ajcn/67.5.1064S

11. Sagripanti JL, Routson LB, Lytle CD (1993) Virus inactivation by copper or iron ions alone and in the presence of peroxide. Appl Environ Microbiol 59:4374-4376

12. Ishida $\mathrm{T}$ (2018) Antiviral activities of $\mathrm{Cu} 2+$ ions in viral prevention, replication, RNA degradation, and for antiviral efficacies of lytic virus, ROS-mediated virus, copper chelation. World Sci News 99:148-168

13. van Doremalen N, Bushmaker T, Morris DH et al (2020) Aerosol and surface stability of SARS-CoV-2 as compared with SARSCoV-1. N Engl J Med 382:1564-1567. https://doi.org/10.1056/ NEJMc2004973

14. Prasad AS (2009) Zinc: role in immunity, oxidative stress and chronic inflammation. Curr Opin Clin Nutr Metab Care 12:646652. https://doi.org/10.1097/MCO.0b013e3283312956

15. Read SA, Obeid S, Ahlenstiel C, Ahlenstiel G (2019) The role of zinc in antiviral immunity. Adv Nutr Bethesda Md 10:696-710. https://doi.org/10.1093/advances/nmz013

16. Yao JS, Paguio JA, Dee EC et al (2021) The minimal effect of zinc on the survival of hospitalized patients with COVID-19: an observational study. Chest 159:108-111. https://doi.org/10.1016/j. chest.2020.06.082

17. te Velthuis AJW, van den Worm SHE, Sims AC et al (2010) $\mathrm{Zn}(2+)$ inhibits coronavirus and arterivirus RNA polymerase activity in vitro and zinc ionophores block the replication of these viruses in cell culture. PLoS Pathog 6:e1001176. https://doi.org/ 10.1371/journal.ppat.1001176

18. Finzi E (2020) Treatment of SARS-CoV-2 with high dose oral zinc salts: a report on four patients. Int J Infect Dis IJID Off Publ Int Soc Infect Dis 99:307-309. https://doi.org/10.1016/j.ijid.2020. 06.006

19. Kanellopoulou C, George AB, Masutani E et al (2019) Mg2+ regulation of kinase signaling and immune function. J Exp Med 216:1828-1842. https://doi.org/10.1084/jem.20181970

20. Ye M, Li Q, Xiao L, Zheng Z (2021) Serum magnesium and fractional exhaled nitric oxide in relation to the severity in asthmachronic obstructive pulmonary disease overlap. Biol Trace Elem Res 199:1771-1777. https://doi.org/10.1007/s12011-020-02314-5

21. Tomo S, Karli S, Dharmalingam K et al (2020) The clinical laboratory: a key player in diagnosis and management of COVID-19. EJIFCC 31:326-346

22. Bahrami A, Arabestani MR, Taheri M et al (2021) Exploring the role of heavy metals and their derivatives on the pathophysiology of COVID-19. Biol Trace Elem Res. https://doi.org/10.1007/ s12011-021-02893-x

23. Fakhrolmobasheri M, Mazaheri-Tehrani S, Kieliszek M, et al (2021) COVID-19 and selenium deficiency: a systematic 
review. Biol Trace Elem Res 1-12. https://doi.org/10.1007/ s12011-021-02997-4

24. Heavy metal content of a medicinal moss tea for hypertension PubMed. https://pubmed.ncbi.nlm.nih.gov/22236074/. Accessed 11 Jan 2022

25. Yadav D, Birdi A, Tomo S, et al (2021) Association of vitamin D status with COVID-19 infection and mortality in the Asia Pacific region: a cross-sectional study. Indian J Clin Biochem IJCB 1-6. https://doi.org/10.1007/s12291-020-00950-1

26. Dharmalingam K, Birdi A, Tomo S, et al (2021) Trace elements as immunoregulators in SARS-CoV-2 and other viral infections. Indian J Clin Biochem IJCB 1-11. https://doi.org/10.1007/ s12291-021-00961-6

27. Taheri M, Bahrami A, Habibi P, Nouri F (2021) A review on the serum electrolytes and trace elements role in the pathophysiology of COVID-19. Biol Trace Elem Res 199:2475-2481. https://doi. org/10.1007/s12011-020-02377-4

28. Li M-Y, Li L, Zhang Y, Wang X-S (2020) Expression of the SARS-CoV-2 cell receptor gene ACE2 in a wide variety of human tissues. Infect Dis Poverty 9:45. https://doi.org/10.1186/ s40249-020-00662-x

29. Jothimani D, Kailasam E, Danielraj S et al (2020) COVID-19: poor outcomes in patients with zinc deficiency. Int J Infect Dis IJID Off Publ Int Soc Infect Dis 100:343-349. https://doi.org/10. 1016/j.ijid.2020.09.014

30. Arrieta F, Martinez-Vaello V, Bengoa N et al (2021) Serum zinc and copper in people with COVID-19 and zinc supplementation in parenteral nutrition. Nutrition 91-92:111467. https://doi.org/ 10.1016/j.nut.2021.111467

31. Anuk AT, Polat N, Akdas S et al (2021) The relation between trace element status (zinc, copper, magnesium) and clinical outcomes in COVID-19 infection during pregnancy. Biol Trace Elem Res 199:3608-3617. https://doi.org/10.1007/s12011-020-02496-y

32. Carlucci PM, Ahuja T, Petrilli C et al (2020) Zinc sulfate in combination with a zinc ionophore may improve outcomes in hospitalized COVID-19 patients. J Med Microbiol 69:1228-1234. https:// doi.org/10.1099/jmm.0.001250

33. Muhammad Y, Kani YA, Iliya S, et al (2021) Deficiency of antioxidants and increased oxidative stress in COVID-19 patients: a cross-sectional comparative study in Jigawa, Northwestern Nigeria. SAGE Open Med 9:2050312121991246. https://doi.org/10. $1177 / 2050312121991246$

34. Zeng H-L, Zhang B, Wang X et al (2021) Urinary trace elements in association with disease severity and outcome in patients with COVID-19. Environ Res 194:110670. https://doi.org/10.1016/j. envres.2020.110670
35. Chen X, Li Y, Zhang T et al (2018) Association of serum trace elements with schizophrenia and effects of antipsychotic treatment. Biol Trace Elem Res 181:22-30. https://doi.org/10.1007/ s12011-017-1039-6

36. Johnson MDL, Kehl-Fie TE, Klein R et al (2015) Role of copper efflux in pneumococcal pathogenesis and resistance to macrophage-mediated immune clearance. Infect Immun 83:16841694. https://doi.org/10.1128/IAI.03015-14

37. Fooladi S, Matin S, Mahmoodpoor A (2020) Copper as a potential adjunct therapy for critically ill COVID-19 patients. Clin Nutr ESPEN 40:90-91. https://doi.org/10.1016/j.clnesp.2020.09.022

38. Hackler J, Heller RA, Sun Q et al (2021) Relation of serum copper status to survival in COVID-19. Nutrients 13:1898. https://doi. org/10.3390/nu13061898

39. Laine JT, Tuomainen T-P, Salonen JT, Virtanen JK (2020) Serum copper-to-zinc-ratio and risk of incident infection in men: the Kuopio Ischaemic Heart Disease Risk Factor Study. Eur J Epidemiol 35:1149-1156. https://doi.org/10.1007/s10654-020-00644-1

40. Maier JA, Castiglioni S, Locatelli L et al (2021) Magnesium and inflammation: advances and perspectives. Semin Cell Dev Biol 115:37-44. https://doi.org/10.1016/j.semcdb.2020.11.002

41. Iotti S, Wolf F, Mazur A, Maier JA (2020) The COVID-19 pandemic: is there a role for magnesium? Hypotheses and perspectives. Magnes Res 33:21-27. https://doi.org/10.1684/mrh.2020. 0465

42. Zeng H-L, Yang Q, Yuan P et al (2021) Associations of essential and toxic metals/metalloids in whole blood with both disease severity and mortality in patients with COVID-19. FASEB J Off Publ Fed Am Soc Exp Biol 35:e21392. https://doi.org/10.1096/ fj.202002346RR

43. Yasui Y, Yasui H, Suzuki K et al (2020) Analysis of the predictive factors for a critical illness of COVID-19 during treatment - relationship between serum zinc level and critical illness of COVID19. Int J Infect Dis IJID Off Publ Int Soc Infect Dis 100:230-236. https://doi.org/10.1016/j.ijid.2020.09.008

44. Heller RA, Sun Q, Hackler J et al (2021) Prediction of survival odds in COVID-19 by zinc, age and selenoprotein $\mathrm{P}$ as composite biomarker. Redox Biol 38:101764. https://doi.org/10.1016/j.redox. 2020.101764

Publisher's Note Springer Nature remains neutral with regard to jurisdictional claims in published maps and institutional affiliations. 